\title{
Production of Encapsulated Organo-Mineral Fertilizers in a Fluidized Bed Granulator
}

\author{
Ruslan Ostroha ${ }^{1, *}$, Mykola Yukhymenko ${ }^{1}$, Olha Lytvynenko ${ }^{1}$ and Andrii Lytvynenko ${ }^{1}$ \\ Sumy State University, 2 Rymskogo-Korsakova St., 40007 Sumy, Ukraine
}

\begin{abstract}
The main disadvantages of using granular nitrogen fertilizers are described. The advantages encapsulated organo-mineral fertilizers are presented. It is proposed to use suspension of chicken manure as an organic shell. One presents the experimental results of coating the carbamide granules with an organic shell in a fluidized bed apparatus. The operating and technological parameters of the encapsulation process in the fluidized bed apparatus have been determined. Analytical relationship for determining the weighted average diameter of suspended particle during the encapsulation process is proposed.
\end{abstract}

Keywords: fluidized bed; suspended layer; coefficient; time

\section{Introduction}

At present, the reasonable use of fertilizers is extremely important for the agroindustrial complex, and it is the impetus for producers and scientists to develop resource-saving technologies for their production. Sufficiently reduce the amount of mineral fertilizers is possible by increasing the efficiency of fertilizers due to using agricultural waste in the production process. Such secondary resources can be waste from livestock, poultry, crop and processing industries, which makes it possible to introduce environmentally friendly technologies in the production of agricultural products.

The range of mineral fertilizers used in all soil types and climatic zones is dominated by nitrogen [1], phosphorus [2] or complex [3] fertilizers.

The top places in the range of nitrogen fertilizers used in all soil types and climatic zones are occupied by ammonium nitrate and carbamide [4]. They are converted in the soil-plant system and are actively included in the general biological nitrogen cycle, providing the needs of plant vegetative system in nitrogen. But along with the known advantages of nitrogen fertilizers there are significant disadvantages - high solubility in water and significant losses from the arable layer, which leads to pollution of surface and groundwater. In addition, the use of high doses of nitrogen fertilizers often leads to accumulation of significant amounts of nitrate nitrogen in the main agricultural products, as well as in the soil, which results in poor product quality and environmental deterioration in the region.

In this regard, it is important to develop and produce such forms of nitrogen fertilizers that have low physiological acidity and prolonged action, which will ensure the efficient use of nitrogen by plants throughout the growing season. First of all, this task is solved by encapsulating the fertilizer - coating the particle surface with the shell which creates additional resistance to mass transfer during the dissolution of fertilizers, and, as a result, reduces unproductive losses of nutrients.

Methods of improving fertilizers quality, wherein it is not required to use significantly complicated technological processes or scarce and expensive reagents

* Corresponding author: Ruslan Ostroha, E-mail:r.ostroga@pohnp.sumdu.edu.ua 
and impurities are of considerable practical interest. The main disadvantage of encapsulated materials compared to non-encapsulated is some higher energy and material costs for their production. That is why the use of chicken manure suspension as a capsule shell material is very up-to-date, as it solves the problem of obtaining organo-mineral fertilizers of prolonged action as well as the problem of organic waste utilization from poultry farms [5]. The fertilizer obtained in this way has prolonged effect and nourishes the plant more productively for a long time, and due to the organic origin of the shell material it is safe for the soil and environment.

The process of applying organic protective shells on fertilizer granules can be termed as encapsulation and granulation as well, because there takes place a significant increase of the granules size comparing with their initial state [6]. Therefore, for arranging such process one can use standard equipment applied for granulation of fertilizers [7]. However, one should note that organic substance, unlike mineral one, has its own peculiarities, which include the possibility of burning and decomposition at high temperatures, increased ability to stick together, lumping.

The aim of the research is to study the mechanism of capsulation fertilizers formation by dehydrating organic suspensions in the fluidized bed, as well as determination of the granulation optimal temperature mode. This enables to improve the technology of organo-mineral fertilizers production and continuously obtain a multilayered product of specified strength and density.

To achieve this aim, it is necessary to solve the following objectives:

- to study the granulation mechanism in the fluidized bed devices;

- to establish granulation temperature mode for chicken manure suspension in a fluidized bed;

- to investigate the kinetics of mineral particle enlargement by coating granule surface with organic substance.

\section{Problem Statement}

Organic wastes are very moist suspensions. Fractional composition of such suspensions is very diverse and they contain many colloidal particles, which form a viscous structure. Therefore, fluidized bed apparatus is proposed to minimize costs on processing wet organic substances for encapsulation purpose $[8,9]$.

They way of obtaining granulation products in the fluidized bed (suspended layer) is used by the world well-known manufacturers of fertilizers and pharmaceutical products: Urea Casale S.A. (Switzerland), Kahl Group (Germany), Stamicarbon (Netherlands), Toyo Engineering Corporation (Japan), Changzhou Xianfeng Drying Equipment Company Ltd (China) Glatt (Germany), Uhde Fertilizer Technology (Netherlands), Rottendorf Pharma (Germany) et al. [10].

The principle of a fluidized bed is used in the apparatus of different designs, operating at different processing modes. However, the processes of granules formation, growth and firming are subjects to single analytic laws [11].

The exact description of the granule growth kinetics is a difficult task, so one uses a number of assumptions to make calculations, as well as empirical and semi-empirical dependences. The main dependences for determining granule growth rate proposed to date, are based on the theory of uniformly-surface enlargement of particles.

One of the first attempts to describe the dependence of a particle size on the granulation process parameters was made by Grimmet, who offered simple and proper arguments [12]. He proceeded from the assumption that all particles uniformly reach the irrigation zone where the system is stationary and mechanisms of the surface growth are the same for each granule. The disadvantage of this technique is its linear direction and the use of ambiguous and difficult definable value - a total surface of the particles in the layer.

In the paper [13] kinetics of the polymer coating increasing on the surface of the spherical particle is expressed by the differential equation of the form:

$d W_{n}=P C d \tau$

where $d W_{n}$ - weight gain of coating on the particle surface, kg; $P$ - consumption of the film-forming solution, which is supplied into the fluidized bed, $\mathrm{m}^{3} / \mathrm{s} ; C$ - polymer concentration in the solution, $\mathrm{kg} /$ $\mathrm{m}^{3}$.

When developing a mathematical model one assumed that all of the particles in a suspended layer are of the same size, on the surface of which there is applied a polymer shell of uniform thickness. Increasing of the shell thickness leads to the particle diameter increase and it is expressed by a differential equation:

$$
d W_{n}=\pi d^{2} N \rho_{a} d \frac{d}{2}
$$


where $N$ - number of particles in the fluidized bed; $\pi d^{2} N$ - total surface of the particles, $\mathrm{m}^{2} ; d(d)$ growth of the particle diameter, $m ; \rho_{a}-$ film-forming agent density, $\mathrm{kg} / \mathrm{m}^{3}$.

Solving of the system of equations (1) and (2) provides a dependence for determining the coating thickness at any time:

$$
\delta=\frac{1}{2} d_{0}\left(\sqrt[3]{1+\frac{P C \rho_{P}}{M_{P} \rho_{a}} \tau}-1\right),
$$

where $\rho_{P}$ - density of the particles, $\mathrm{kg} / \mathrm{m}^{3} ; M_{P}$ - total mass of the particles, $\mathrm{kg}$.

Equation (3) is «rough», that is not enough valid. This model sets aside a probability of increasing the shell in a fluidized bed.

In the paper [14] one uses Todes continuity equation which mathematical model has the form:

$$
\begin{aligned}
& \frac{\partial g}{\partial \tau}+2 \cdot\left[\Lambda \frac{\partial g}{\partial D}+g \frac{\partial \Lambda}{\partial D}-\frac{3 \Lambda g}{D}\right]= \\
= & -S \psi K g+\phi(D) ; \tau>0 ; 0<D<\infty
\end{aligned}
$$

where $g$ - function of the granule mass distribution in size, $\mathrm{mm}^{-1} ; \tau$ - time, $\mathrm{h} ; D$ - current granule diameter, $\mathrm{mm} ; \boldsymbol{\Lambda}$ - linear growth rate of the granules, $\mathrm{mm} / \mathrm{h} ; S$ - function separator; $\psi$ - granule formation coefficient, fractions; $K$ - unload constant, $\mathrm{h}^{-1} ; \varphi(D)$ - power function of the new granulation center source $(\mathrm{mm} \cdot h)^{-1}$.

To solve the equation (4) empirically one determines granule formation coefficient $\psi$, linear growth rate of the granules $\boldsymbol{\Lambda}$, unload constant $K$ and the function of granule mass distribution in size g.

One suggested the following equation for particle size distribution function:

$$
\begin{aligned}
& F\left(D_{i} ; D_{O K}\right)= \\
= & 1-\exp \left\{-\frac{3 \cdot\left[G_{R}+\left(1-K_{G R}\right) \cdot G_{M}\right]}{K_{G R} \cdot G_{M}} \cdot \ln \frac{D_{i}}{D_{O K}}\right\}
\end{aligned}
$$

where $K_{G R}$ - granule formation coefficient; $G_{M}$ - granulator performance, $\mathrm{kg} / \mathrm{h} ; G_{R}$ - cycle performance, $\mathrm{kg} / \mathrm{h} ; D_{i}$ - current diameter, $\mathrm{mm} ; D_{O K}$ - cycle particle size, $\mathrm{mm}$.

To solve the equation (5) it is necessary to determine by experimental way the $K_{G R}$ value and to know the exact size of the new granulation centers formed during the process.

In [15] it is noted that the increase of the coating mass on the surface of the granules depends on the consumption of the film-forming solution, which is fed into the suspended layer of particles and the size of the sprayed drop.

Thus, experimental selection of an optimal mode for carrying out the process of granule formation when encapsulating mineral granules with an organic shell is very important.

\section{Experimental Materials and Methods}

Experimental studies of polydisperse granules enlargement were performed on a specially designed laboratory unit (Fig. 1) during a single loading of granular material and two constant modes of feeding the suspension (10 and $20 \mathrm{ml} /$ $\min )$.

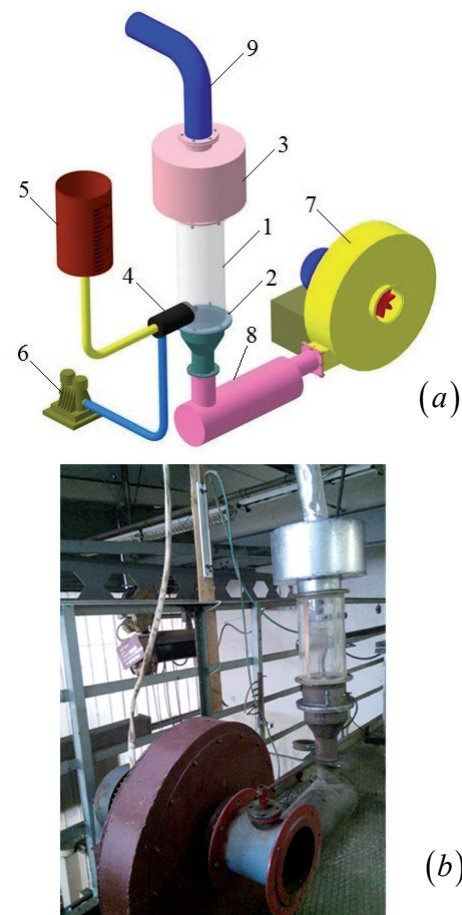

Figure 1: Scheme (a) and photograph (b) of the laboratory unit for encapsulation of granular fertilizers: 1 - working chamber; 2 - air distributor; 3 - device head; 4 - pneumatic nozzle; 5 measuring tank; 6 - compressor; 7 - blower; 8 - heater; 9 - air corrugation.

Carbamide granules were used as a starting product. A pneumatic nozzle (Fig. 2) was mounted on the side of the apparatus, approximately in the middle part of the fluidized bed, wherein compressed air and suspended organics (a mixture of liquid and small (10-20 $\mu \mathrm{m})$ organic particles) were introduced. 

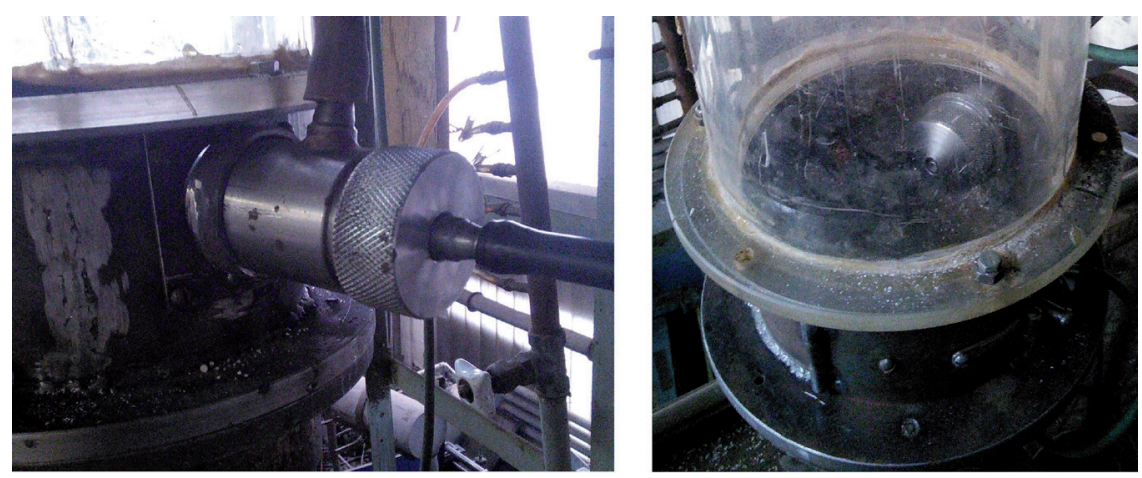

Figure 2: Location of the pneumatic nozzle.

Prior to entering the measuring tank, the initial organics (liquid chicken manure) goes through fine three-stage grinding on a laboratory disk mill. Chicken manure is introduced into the working section (grinding area), enclosed on both sides with abrasive wheels. Under the action of cutting and tensile forces destruction (erasure) of suspension solid inclusions takes place in this section. After each stage of grinding, the gap between the circles decreases. Thus, after the third processing stage one obtains fine homogeneous mass.

Therefore, a portion of polydisperse carbamide in the amount of $0.5 \mathrm{~kg}$ was fed into the air distributor plate 2 (Fig. 1). First, the gas blower 7 was started, and next the heater 8 was turned on. For the study one set the required rate of ascending air flow, which created a fluidized bed. Using a pneumatic nozzle 4 a suspension of chicken manure was introduced into the layer of suspended granules. Every 20 minutes of the encapsulation process, the laboratory unit was stopped and sieve analysis of the granules was performed. Then the unit was restarted and the experiment continued, i.e., for each subsequent 20-minute period of time, the source product loaded into the working chamber 1 was the final granules obtained from the previous period of the experiment.

\section{Results}

Study results of the kinetics of carbamide granules enlargement during their encapsulation with chicken manure in a fluidized bed for the periodic mode of apparatus operation are shown in Fig. 3.

The obtained histograms show that only initial granules are characterized by a bimodal form of the distribution function, i.e. there are two distinctive maxima. It goes to confirm the fact that carbamide granules were obtained by rolling in drum granulators, wherein two parallel processes take place: first one is aimed at increasing particle size - normal growth, and reverse process caused by abrasion of the granules surface, during their intensive rolling. New centers of granulation are formed in the drum, which leads to an increase of the small granules amount in the mixture.

Further, during the encapsulation process, the distribution function changes its shape and there is only one maximum value. It means that under the working conditions of encapsulation, the organic substance is fixed on the surface of the particles, covering them with a firm layer, which is not chipped off the granule surface.
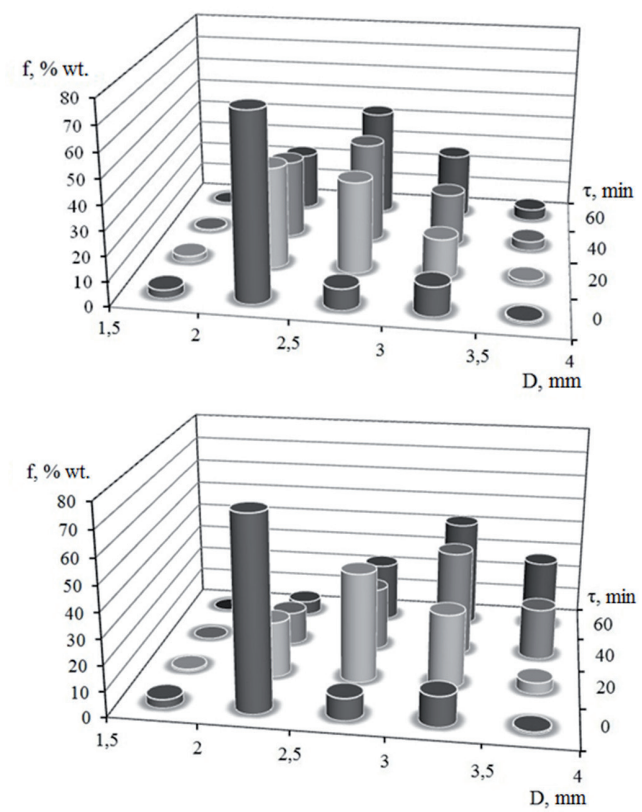

(b)

Figure 3: Histograms of particle size distribution at different points in time during the encapsulation process in the case of suspension consumption: (a) $10 \mathrm{ml} / \mathrm{min}$; (b) $20 \mathrm{ml} / \mathrm{min}$. 
The temperature under the air distributor plate is regulated in the range of $75-85^{\circ} \mathrm{C}$, and the temperature in the layer of granules is of slightly lower values. The decrease in temperature in the layer is a consequence of the wet suspension introduction, which evaporates and thus absorbs heat.

The process of carbamide granules encapsulation with chicken manure in the laboratory is characterized by reasonable mode and technological parameters (Table 1).

Table 1: Mode and technological parameters of the encapsulation process in the fluidized bed device.

\begin{tabular}{|l|l|l|}
\hline Parameter & \multicolumn{3}{|l|}{ Value } \\
\hline Consumption of liquid suspension (chicken manure), $\mathrm{ml} / \mathrm{min}$ & 10 & 20 \\
\hline Weight of mineral granules in the device, $\mathrm{kg}$ & 0.5 & \\
\hline Weighted average diameter of the initial granules, $\mathrm{mm}$ & 2 & \\
\hline Air supply rate, $\mathrm{m} / \mathrm{s}$ & 4.8 & \\
\hline Hydraulic resistance, $\mathrm{Pa}$ & 580 & 610 \\
\hline Air temperature under the air distributor plate, ${ }^{\circ} \mathrm{C}$ & 80 & \\
\hline Air temperature in the dispersed material laver, ${ }^{\circ} \mathrm{C}$ & 65 & \\
\hline Process time, min & 50 & \\
\hline Proportion of organic shell in the total weight of the granules, $\% \mathrm{wt} .^{\mathrm{N}}$ & 35 & 50 \\
\hline
\end{tabular}

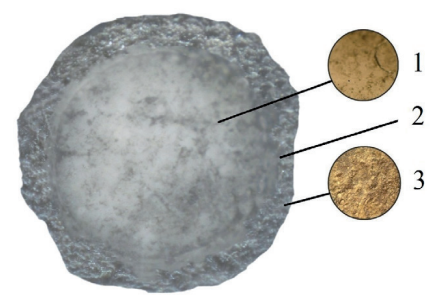

(a)

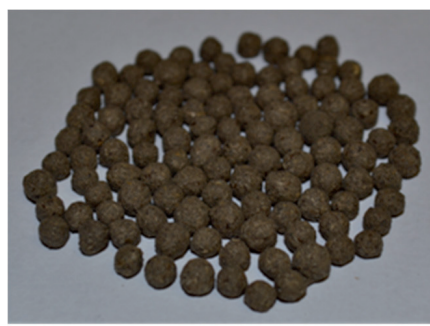

Figure 4: Structure (a) and general appearance (b) of granules with prolonged action.

\section{Discussion}

The main indicator of quality coating in the encapsulation of mineral fertilizer granules with chicken manure is the shell of specific thickness, smoothly distributed over the entire granule surface, which provides full coating of mineral granules with the organic substance layer (Fig. 4).
Therefore, the optimal operating mode is reached at a temperature of $60-65^{\circ} \mathrm{C}$ in the layer of granules.

Polydisperse granules enlargement in the fluidized bed was monitored by increasing their weighted average diameter using the following equation:

$D=D_{0} \exp \left(\frac{g_{0} \cdot \tau}{\psi}\right)$

where $D_{0}$ is the weighted average diameter of the initial granules, $\mathrm{mm} ; g_{0}$ - specific consumption of the shell material (divided into the mass of initial granules), $\mathrm{kg} /(\mathrm{kg} \cdot \mathrm{s}) ; \tau$ - process time, $\mathrm{s} ; \psi-$ empirical coefficient that depends on the number of fluidization (operating air velocity), mode parameters of the nozzle, ratio of the layer height and the spray height, and so on.

In this case, the weighted average diameter was determined by:

$D_{W . A .}=\sum D_{i} \cdot x_{i}$

where $D_{i}, x_{i}$ - diameter and mass content of granules of the i-fraction, respectively.

Approximating the experiment results, we obtain equation (6) of the following form:

$D=D_{0} \exp \left(\frac{g_{0} \cdot \tau}{7.5 \cdot 10^{-4} \cdot \tau+1.74}\right)$

\section{Conclusions}

The mechanism of organo-mineral granule formation in a fluidized bed device is studied and the influence of temperature on the granulometric composition of the final product is determined. At a temperature of $60-65^{\circ} \mathrm{C}$, one can continuously obtain commodity product of high density and strength in a layer of suspended granules.

Studied experimentally and theoretically the kinetics of mineral granules enlargement during their encapsulation with organic substance.

The proposed method of coating mineral fertilizer granules with an organic suspension in a fluidized bed apparatus makes it possible to increase the utilization coefficient of the obtained fertilizers, minimize the quantity of their application in soil, and due to the organic origin of the shell, reduce environmental pollution.

The production of many bulk granular products is currently based on several typical processing schemes. When developing technological schemes 
for producing a granular product, developers and designers encounter difficulties in selecting the necessary equipment for operating departments of production, namely, for granulation and enlargement of granules, their drying, cooling, and pneumatic separation. Thus, further research in the field of intensification of disperse systems processes need to be directed to the development, first of all, of energy-saving fluidized-bed apparatus, with new organizing of gas-dispersed flows. Multistage fluidized bed gravitational devices met these requirements, wherein high efficiency and multifunctional performance are combined with minimal costs for carrying out target processes and dust cleaning.

\section{Acknowledgments}

This research work has been supported by Education of Ukraine under the project "Small-scale energy-saving modules with the use of multifunctional devices with intensive hydrodynamics for the production, modification and encapsulation of granules" (Project No. 0119U100834).

\section{References}

1. Jarchow, M. E., Liebman, M. (2013). Nitrogen fertilization increases diversity and productivity of prairie communities used for bioenergy. GCB Bioenergy, 5, 3, 281-289.

2. Khiari, L., Parent, L.-E. (2005). Phosphorus transformations in acid light-textured soils treated with dry swine manure. Canadian Journal of Soil Science, 85, 75-87.

3. Yukhymenko, M. P., Vakal, S. V. (2016). The exergy analysis of energy efficiency of the technology of granulated phospohrus-potassium fertilizers. Eastern-European Journal of Enterprise Technologies, 5, 6, 4-10.

4. Galichechi, S., Gashti azar, M. (2013). Nitrogen fertilizer the effects on growing potato. Journal of Biology and Today's World, 2, 335-338.

5. Ostroha, R. O., Yukhymenko, M. P., Mikhajlovskiy, Y. E., Litvinenko, A. V. (2016). Technology of producing granular fertilizers on the organic basis. Eastern-European Journal of Enterprise Technologies, 1, 6, 19-26.

6. Hu, X., Cunningham, J. C., Winstead, D. (2008). Study growth kinetics in fluidized bed granulation with at-line FBRM International Journal of Pharmaceutics, 347, 1-2, 54-61.

7. Gupta, R. (2017). Fluid bed granulation and drying. Predictive Modeling of Pharmaceutical Unit Operations, 6, 137-158.

8. Sheng, T. C., Sulaiman, S. A., Kumar, V. (2012). Onedimensional modeling of hydrodynamics in a swirling fluidized bed. International Journal of Mechanical \&
Mechatronics Engineering, 12, 6, 13-22.

9. Gupta, S. K., Singhvi, I. J., Shirsat, M. K., Karwani, G., Agarwal, A., Aditi (2011). Microencapsulation techniques and its application in pharmaceutical. Asian Journal of Pharmaceutical Sciences and Clinical Research, 1, 3, 67-77.

10. Saikh, M. A. (2013). A technical note on granulation technology: a way to optimise granules. International Journal of Pharmaceutical Sciences Review and Research 4, 55-67.

11. Dimin, M. F., Loh, M. K., Jamli, M. R, Sued, M. K., Munawar, R. F. (2019). Fluidized bed granulation parameters effect on urea granule physical properties. Journal of Applied Fluid Mechanics, 12, 2, 495-503.

12. Grimmett, E. S. (1964). Kinetics of particle growth in the fluidized bed calcinations process. AJCHE Journal, 10, 5 , 717-722.

13. Malovanyi, M. S., Nahurskyi, O. A., Bunko, V. Y., Druziuk, V. M. (2012). Teplomasoobmin protsesu kapsuliuvannia mineralnykh dobryv vodnym rozchynom plivkoutvoriuiuchoi kompozytsii palyhorskit - meliasa. Visnyk Kremenchutskoho NU im. Mykhaila Ostrohradskoho, 2, 117-120.

14. Kornienko, Y., Sachok, R., Rayda, V., Tsepkalo, O. (2009). Mathematical modeling of continuous formation of multilayer humic-mineral solid composites. Chemistry \& Chemical Technology, 4, 335-338.

15. Rao Patnaik, K. S. K., Sriharsha, K. (2010). Granule growth mechanism studies in a fluidized bed granulation. International Journal of Chemical Engineering and Applications, 1, 3, 282-286. 